\title{
The Relationship between Learning Styles and Cognitive Traits - Getting Additional Information for Improving Student Modelling
}

\author{
Sabine Graf ${ }^{\mathrm{a}}$, Taiyu Lin ${ }^{\mathrm{b}}$, Kinshuk ${ }^{\mathrm{c}}$ \\ a'Women's Postgraduate College for Internet Technologies, Vienna University of Technology, Vienna, \\ Austria \\ ${ }^{\mathrm{b}}$ Department of Information Systems, Massey University, Palmerston North, New Zealand \\ ${ }^{\mathrm{c}}$ School of Computing \& Information Systems, Athabasca University, Canada
}

\begin{abstract}
Student modelling is an important process for adaptive virtual learning environments. Student models include a range of information about the learners such as their domain competence, learning style or cognitive traits. To be able to adapt to the learners' needs in an appropriate way, a reliable student model is necessary, but getting enough information about a learner is quite challenging. Therefore, mechanisms are needed to support the detection process of the required information. In this paper, we investigate the relationship between learning styles, in particular, those pertaining to the Felder-Silverman learning style model and working memory capacity, one of the cognitive traits included in the Cognitive Trait Model. The identified relationship is derived from links between learning styles, cognitive styles, and working memory capacity which are based on studies from literature. As a result, we demonstrate that learners with high working memory capacity tend to prefer a reflective, intuitive, and sequential learning style whereas learners with low working memory capacity tend to prefer an active, sensing, visual, and global learning style. This interaction can be used to improve the student model. Systems which are able to detect either only cognitive traits or only learning styles retrieve additional information through the identified relationship. Otherwise, for systems that already incorporate learning styles and cognitive traits, the interaction can be used to improve the detection process of both by including the additional information of a learning style into the detection process of cognitive traits and vice versa. This leads to a more reliable student model.
\end{abstract}

\section{Keywords}

Felder-Silverman learning style model, cognitive trait model, working memory capacity, student model 


\section{Introduction}

Student models (for example, see Brusilovsky, 1994) are essential to any adaptive virtual learning environments. These models contain information about learners such as personal data, domain competence, learning style and cognitive traits, and use this information to adapt to the learners' needs. An important task for such adaptive environments is to build a robust student model in order to be able to provide adaptivity in an appropriate way, but filling the student model with proper information about the learner is quite challenging.

The simplest approach to construct a student model is to ask a student for relevant data. However, this approach is not suitable for identifying accurate information for a number of components of a student model, such as cognitive traits, domain competence, and preferred learning styles. For example, the estimation of domain competence is subjective. To determine cognitive traits and learning styles, comprehensive tests or questionnaire-based surveys are the ordinary means used but these are time consuming and hardly definitive. An alternative approach to collect the information pertinent to a student model is to track the student's behaviour and responses and then make inferences about general domain competence, cognitive traits, and learning styles. The challenge of this approach is to identify and collect sufficient information to make reliable and useful inferences. To support the detection process of required information, it is beneficial to find mechanisms that use whatever information about the learner is already available to obtain as much reliable information as possible to build a more robust student model.

The aim of this paper is to demonstrate the relationship between the learning style and the cognitive traits of a learner. The identified relationship provides additional information which can be used to improve the detection process of both, the learning style and the cognitive traits, in an adaptive virtual learning environment.

To exemplify this relationship, we investigate the interaction of working memory capacity, one cognitive trait included in the Cognitive Trait Model (Lin, Kinshuk, and Patel, 2003), with Felder-Silverman learning style model (Felder and Silverman, 1988). Both models as well as their possible implementation in adaptive virtual learning environments are described in the next section in more detail. In Section 3, we present the mapping between the Felder-Silverman learning style model and working memory capacity. This mapping is 
derived from links between learning styles, cognitive styles, and working memory capacity which are based on studies from literature. Section 4 points out the results as well as the benefits of the identified relationship. Section 5 then concludes the paper.

\section{Description of the Learning Style Model and the Cognitive Trait Model}

In this section, two models - the Felder-Silverman learning style model (FSLSM) and the Cognitive Trait Model (CTM) - are explained to provide background information for the current investigation. While several learning style theories exist in literature, for example, the learning style model by Kolb (1984) and Honey and Mumford (1982), FSLSM seems to be most appropriate for the use in educational systems. Most other learning style models classify learners as belonging to a few groups, whereas Felder and Silverman describe the learning style of a learner in more detail, distinguishing between preferences on four dimensions. Another main issue is that FSLSM is based on tendencies, indicating that learners with a high preference for a certain behaviour can act sometimes differently. The description of FSLSM focuses on the different dimensions as well as the characteristic behaviour and preferences of learners for each dimension. The use of this learning style model in virtual learning environments is briefly discussed, focusing on how to approach filling the student model with information about the learning style. Regarding the Cognitive Trait Model, an insight into how the model can be used and how cognitive traits can be identified in virtual learning environments is provided.

\subsection{The Felder-Silverman Learning Style Model}

Felder-Silverman learning style model (Felder and Silverman, 1988) characterizes each learner according to four dimensions. The first dimension distinguishes between an active and a reflective way of processing information. Active learners learn best by working actively with the learning material, for example, working in groups, discussing the material, or applying it. In contrast, reflective learners prefer to think about and reflect on the material. 
The second dimension covers sensing versus intuitive learning. Learners with a sensing learning style like to learn facts and concrete learning material, using their sensory experiences of particular instances as a primary source. They tend to be more patient with details and also more practical than intuitive learners and like to relate the learned material to the real world. Intuitive learners prefer to learn abstract learning material, such as theories and their underlying meanings, with general principles rather than concrete instances being a preferred source of information. They like to discover possibilities and relationships and tend to be more innovative and creative than sensing learners. Therefore, they score better in open-ended tests than in tests with a single answer to a problem. This dimension differs from the active-reflective dimension in an important way: the sensing-intuitive dimension deals with the preferred source of information whereas the active-reflective dimension covers the process of transforming the perceived information into knowledge.

The third, visual-verbal dimension deals with the preferred input mode. The dimension differentiates learners who remember best what they have seen, e.g. pictures, diagrams and flow-charts, from learners who get more out of textual representations, regardless of the fact whether they are written or spoken.

In the fourth dimension, the learners are characterized according to their understanding. Sequential learners learn in small incremental steps and therefore have a linear learning progress. They tend to follow logical stepwise paths in finding solutions. In contrast, global learners use an holistic thinking process and learn in large leaps. They tend to absorb learning material almost randomly without seeing connections but after they have learned enough material they suddenly get the whole picture. Then they are able to solve complex problems and put things together in novel ways but they have difficulties in explaining how they did it.

Each learner has a preference in each of the four dimensions. These preferences are expressed by values between +11 to -11 per dimension (Felder and Soloman, 1997). Using the active-reflective dimension as an example, the value +11 means that a learner has a strong preference for active learning, whereas the value -11 states that a learner has a strong preference for reflective learning. Therefore, Felder-Silverman learning style model characterizes each learner by four values between +11 and -11 , one for each dimension. For identifying the learning style of learners, Felder and Soloman (1997) developed a questionnaire, called the Index of Learning Style (ILS), which consists of 44 questions: 11 for each dimension. 
The first adaptive hypermedia system based on FSLSM was CS383 (Carver, Howard, and Lane, 1999). The course conducted in the system included a comprehensive collection of media objects. The system offered students the option to order these media objects in accordance with how well they fit to the learning style of the student. Another example is MAS-PLANG (Peña, Marzo, and de la Rosa, 2002), a multi-agent system which has been developed to enrich the intelligent tutoring system USD (Fabregat, Marzo, and Peña, 2000) with adaptivity with respect to learning styles. Both CS383 and MASPLANG used ILS for initializing the student model according to learning styles.

Another approach, besides letting students fill out a questionnaire, is to use the behaviour of students during an online course to infer their learning styles from this behaviour. For example, García, Amandi, Schiaffino, and Campo (2006) studied the use of Bayesian networks to detect students' learning styles in the educational system SAVER. They determined several patterns for three dimensions (active/reflective, sensing/intuitive, and sequential/global) of FSLSM. According to the behaviour of the students in the online course, the probability of the preferred learning style was calculated by the use of Bayesian networks. Subsequently, the probability values were mapped to the scale proposed by Felder. While this approach is developed for a specific system, Graf and Kinshuk (2006) proposed an approach to detect learning styles in learning management systems in general. They determined general patterns for all four dimensions of FSLSM. The calculation of learning styles is based on the approach used in ILS. Therefore, each pattern indicates either a preference for one or the other style of the dimension, or respectively no preference. As a result, the values of the patterns for each dimension were summed up and scaled.

\subsection{The Cognitive Trait Model}

Cognitive Trait Model (CTM) (Lin, Kinshuk, and Patel, 2003) is a student model that profiles learners according to their cognitive traits. Three cognitive traits, working memory capacity, inductive reasoning ability, and associative learning skills are included in CTM so far. In the current investigation involving CTM and FSLSM, only working memory capacity is covered, and hence discussed below.

In earlier times, working memory was also referred to as short-term memory. Richards-Ward (1996) named it the Short-Term Store (STS) to emphasise its role of temporal storage of recently perceived 
information. STS allows us to keep active a limited amount of information (roughly 7+-2 items) for a brief period of time (Miller, 1956). Baddeley (1986) tried to study and understand the working memory by decomposing it into components. The structure of working memory consists of a Central Executive, a Phonological Loop, and a Visual-Spatial Sketch-Pad. The Central Executive is the controlling component in working memory: it is in charge of the allocation and co-ordination of tasks. The Phonological Loop is the slave component for verbal information processing and storage. The Visual-Spatial Sketch-Pad is the slave component for visual/graphical information processing and storage. The Central Executive takes the role to monitor and control the output of the two slave-systems, and selects what is relevant for potential processing (Richards-Ward, 1996).

While Baddeley (1986) defined working memory in terms of structures, others have defined working memory in terms of processes (Salthouse, Mitcheel, Skovronek, and Babcock, 1989). Salthouse et al. (1989) proposed that working memory consists of (a) a storage capacity sensitive to the number of items presented, and (b) an operational capacity sensitive to the number of operations performed on items. The structure of working memory was not emphasised in this view. The processing/operational efficiency was regarded as the sole determinant of the performance of working memory. A further study of the operational efficiency of working memory showed that it was not the operational capacity (number of operations allowed) contributing the most to the efficiency of working memory, but it was actually the speed of execution (e.g. comparison speed) that determined the performance of the overall system of working memory (Salthouse and Babcock, 1991). Even though these two different points of view do not agree on a common structure of working memory, they both agree that working memory consists of both storage and operational sub-systems (Richards-Ward, 1996).

The proposition of CTM changes the traditional idea of the student model that is thought of as just a database sitting on the server which is full of numbers for only a particular task. The CTM offers the role of 'learning companion', which can be consulted by and interacted with different learning environments about a particular learner. The CTM can still be valid after a long period of time due to the more or less persistent nature of cognitive traits of human beings (Deary, Whiteman, Starr, Whalley, and Fox, 2004). Furthermore, cognitive traits can be seen as domain and context independent (Kinshuk and Lin, 2005). When a student encounters a new learning environment, the learning environment can directly use the CTM of the particular 
student from a Universal Resource Locator (URL) in the Internet or portable storage media of the student. The learning environment does not need to reconstruct a model of that student. The CTM can also be saved to portable electronic media, such as a flash drive, and accessed every time the student starts up a learning session. In this sense, the CTM is like a learning companion who even though it does not know what is to be learned, knows how the learning content can be best presented to the student. The CTM also stands as a cognitive facilitator between the student and the learning environment.

Figure 1 shows a typical structure of CTM. The learner interface provides a presentation of the learning environment to interact with the learner. In web-based systems, the learner interface is generally implemented inside a Web browser. Due to the stateless nature of the HTTP protocol used by Web browsers, it is necessary to embed a mechanism that can monitor events created by a learner's interactions with a learning environment. The mechanism is represented by the Interface Listener Component in Figure 1. Learner interactions are interpreted as a series of learner actions performed on knowledge objects. Actions are then passed on to the Action History Components and are stored in the Action History.

The performance-based model typically exists independently in the adaptive educational system. It represents the learner's domain competence and models the problem-solving process that the learner undertakes. Certain learner behaviours, called Manifestation of Traits (MOTs), can be used to infer about the cognitive capacity. Information of the performance-based model, such as passing or failing a unit, can be useful for detecting MOTs of some cognitive traits, and therefore data in the performance-based model is used as a source by the MOT Detector Component.

\section{Insert Figure 1 about here}

Various MOTs are defined for each cognitive trait. Each MOT is a piece of an interaction pattern that manifests certain learner characteristic (e.g., low working memory capacity). The MOT Detector Component contains knowledge about a number of MOTs and detects those MOTs within a series of actions that are requested from the Action History Component. Each MOT belongs to one of the two groups (low or high) of 
a particular cognitive trait, and each MOT belongs to only one particular Individualised Temperament Network.

The Individualised Temperament Network (ITN) Component in Figure 1 can have more than one Individualised Temperament Network (Lin and Kinshuk, 2004). Each ITN represents a particular cognitive trait (e.g. working memory capacity) of the learner. Each node in the ITN has a weight and corresponds to an MOT. Once a MOT is detected from the learner's actions, the corresponding node is activated. The result of the execution of an ITN determines how the nodes in the ITN should be updated. The results of the execution of the ITNs are then saved in the Cognitive Trait Model via the trait model gateway.

\section{Mapping of the Felder-Silverman Learning Style Model to the Cognitive Trait Model}

In this section the relationship between one cognitive trait, namely working memory capacity, and each of the dimensions of the Felder-Silverman learning style model (FSLSM) is described. This interaction can be used to support the identification process of both, learning styles and cognitive traits.

In our investigations we also incorporated cognitive styles. One of the most extensively studied cognitive styles with wide application to educational problems is the field-dependence/field-independence dimension (Witkin, Moore, Goodenough, and Cox, 1977 quoting Witkin, Dyk, Faterson, Goodenough, and Karp, 1962/1974; Witkin, Lewis, Hertzman, Machover, Meissner, and Wapner, 1954/1972; Witkin, 1976). The perception of a field-dependent person is strongly dominated by the prevailing field whereas a fieldindependent person experiences items more or less separate from the surrounding field. Therefore, a fieldindependent person is likely to overcome the organization of a field or restructure it whereas a fielddependent person tends to adhere to the organization of the field as given. A main characteristic of fieldindependent people is that they tend to be more analytical and also more interested in abstract and theoretical issues, whereas field-dependent people tend to be more attentive to the social frames of reference and are therefore considered as more socially oriented. Field-dependent people are described as warm, tactful, considerate, socially outgoing, affectionate by others, as well as know and be known by more people. Field- 
independent people are more impersonally orientated and are described as cold, individualistic, and unaware of their social stimulus value. (Witkin et al., 1977)

Several studies exist in the literature showing that field-dependent students generally have low working memory capacity and field-independent students have high working memory capacity (Al-Naeme, 1991; Bahar and Hansell, 2000; El-Banna, 1987; Pascual-Leone, 1970). Furthermore, there are some relations between the field-dependent/field-independent dimension and dimensions of FSLSM. Thus, we additionally use this interaction to make indirect relationships between working memory capacity and dimensions of FSLSM.

The thinking style introduced by Hudson (1966) can also be used for linking FSLSM to CTM. According to Hudson, there exist two styles of thinking: convergent and divergent. People using a convergent style of thinking are good in dealing with facts and bringing them together for solving problems that ask for one solution. This is the required type of thinking in conventional intelligence tests (Santrock, 2005). Therefore, convergent learners tend to score better in this kind of test and are defined as high IQ learners by Hudson. In contrast, divergent learners have their strength in creativity. They tend to be good in thinking in novel ways, coming up with unconventional solutions, and creating a great variety of ideas out of a given stimulus. Therefore, they are considered as highly creative learners who score better in open-ended tests where not only one single correct answer is asked but learners have to use their creativity in order to find possible solutions.

Bahar and Hansell (2000) investigated the relationship between the convergent and divergent cognitive styles (Hudson, 1966), the field-dependence/field-independence dimension (Witkin et al., 1977), and working memory capacity. Furthermore, they studied the effect of these psychological factors on the performance of word association tests and the grid type of questions. They conducted a study with about 400 students and let students perform tests to measure their psychological factors as well as a word association test and grid questions. For our investigations, only the findings about the interactions between field-dependence and field-independence dimension, convergent and divergent styles, and working memory capacity are of particular interest. According to the students' scores of the personality tests, a significant positive correlation between the field-dependent cognitive style and low working memory capacity and the field-independent cognitive style and high working memory capacity was identified. This relation is in line with several other 
studies, as discussed above. Moreover, the result of the study showed a significant positive correlation between students' convergence/divergence test results and the results of the working memory capacity test. According to this, divergent students tend to have a high working memory capacity and convergent students tend to have a low working memory capacity. No significant relationship was found between the convergent/divergent style and field-dependence/field-independence, but tendencies indicate that divergent learners are more likely to prefer a field-independent cognitive style and convergent learners tend to prefer a field-dependent cognitive style. In summary, the study shows that there is an overlap between a convergent thinking style, low working memory capacity, and field-dependence. In contrast, an interaction exists between divergent thinking, high working memory capacity, and field-independence.

An important link between working memory and learning style can be found through literature on dyslexia. The term dyslexia refers to specific learning difficulty regarding written language (Jeffries and Everatt, 2004). Simmons and Singleton (2000) studied a group of dyslexic university students by comparing their reading comprehension ability with non-dyslexic students, and found that "dyslexic students were specifically impaired in constructing inferences when processing complex text” (p. 178). No difference was found between the dyslexic and non-dyslexic groups when literal questions, which only required information that was explicitly stated in the text, were given. However, significant differences were found when inferential questions were given, which required the students to integrate more than one piece of information or use their prior knowledge to interpret an ambiguous statement. Dyslexic students did not do very well in inferential questions and the cause was found to be working memory deficiency (Simmons and Singleton, 2000). Beacham, Szumko, and Alty (2003) pointed out that dyslexics have weakness also in other cognitive abilities including short-term memory, sound processing, co-ordination and motor skills, and visual processing. Calvo's (2001) experiment of the reading-span task also provided evidence that working memory is essential for elaborative inference during reading by taking an important role in the text-integration process. The inferential ability takes the role of bridging the gap between the necessary semantics and thus it is called bridging inferential (Calvo, 2001).

Beacham, Szumko, and Alty (2003) studied the effect of different presentation modes in e-learning courses for dyslexic students. All students performed the ILS questionnaire in order to provide information about their learning styles. As argued by Simmons and Singleton (2000) citing Beech, 1997; Hanley, 1997; 
Nicolson and Fawcett, 1997; and Palmer, 2000, dyslexics have impaired working memory capacity. Although these studies did not clearly answer whether the relationship between low working memory and dyslexia is bi-directional (i.e. low working memory implies dyslexia and dyslexia implies low working memory), nonetheless they gave support to our argument that lower working memory learners tend to have a poorer reading ability.

\subsection{Working Memory Capacity and the Sensing-Intuitive Dimension}

According to Hudson (1966), divergent students are very similar to intuitive students. Both tend to be creative and score better in open-ended tests than in tests where only a single answer is asked. In contrast, convergent students have strong similarities with sensing students. Based on these similarities and on Bahar and Hansell's (2000) results regarding the relationship between convergence/divergence and working memory capacity, it can be concluded that sensing learners tend to have low working memory capacity whereas intuitive learners tend to have high working memory capacity.

Another main feature of the sensing-intuitive dimension is the concrete-ness (as opposed to abstract-ness) of preferred learning material. According to Witkin et al. (1977) quoting the work of Biggs, Fitzgerald, and Atkinson (1971); Heath (1964); Jay (1950); Pemberton (1952); and Stidham (1967), a characteristic of fieldindependent learners is that they tend to be more interested in abstract and theoretical issues. Because intuitive learners are also described to have a preference to learn abstract material such as concepts and theories, an overlap can be seen in an intuitive learning style and a field-independent cognitive style. This interaction is also confirmed, for example, by studies of Davis (1991) as well as of Ford and Chen (2000), saying that in contrast field-dependent learners, like sensing learners, prefer concrete material, whereas fieldindependent learners, like intuitive learners, prefer to learn abstract material. As a consequence of the interaction between working memory capacity and field-dependence/independence, this is another pointer arguing that sensing learners are likely to be field-dependent and therefore tend to have low working memory capacity, whereas intuitive learners tend to have a field-independent cognitive style and high working memory capacity. 
Furthermore, an association can be found between working memory capacity and concreteness/abstractness in structural learning theory (Scandura, 1973). Structural learning theory postulates that the information learned are rules. In order to identify and learn low-order (fundamental) rules, learners should be presented with representative problem samples of the low-order rules and the corresponding solutions prior to given high-order (advanced) rules. The number of representative problem samples should increase for learners with low working memory capacity so that they can grasp low-order rules first and use them to generate high-order rules (Kinshuk and Lin, 2005). From the line of inference according to the structural learning theory, learners with low working memory capacity and sensing learners can be similarly categorized by having preference for learning with examples. Similarly, learners with high working memory capacity and intuitive learners can be categorized to have a preference for learning with abstract concepts.

The investigations above have shown a relationship between working memory capacity and the sensingintuitive dimension of FSLSM. Learners with high working memory capacity tend to have an intuitive learning style whereas learners with low working memory capacity tend to have a sensing learning style.

\subsection{Working Memory Capacity and the Active-Reflective Dimension}

Hudson (1966) and Kolb (1984) both used the terms “divergent” and “convergent”. Although Hudson distinguished them as thinking styles and Kolb examined them as learning styles, there is a strong relationship between both. In both, Hudson’s (1966) and Kolb’s (1984) studies, divergent learners are defined as creative, and convergent learners are defined as those who do best when there is only a single answer to a problem. Additionally, Kolb’s learning style model relates the four learner types (Diverger, Converger, Assimilator, and Accommodator) to the dimension of doing versus watching as well as to the dimension of feeling versus thinking. Convergers are related to active experimentations (doing) and Divergers are related to reflective observations (watching). Therefore, Divergers and Convergers refer not only to the sensing-intuitive dimension of FSLSM but also to the active-reflective dimension. Since Convergers are found to have a low working memory capacity and Divergers high working memory capacity (Bahar and Hansell, 2000), a relationship between an active-reflective learning style and working memory capacity can thus be established. 
This relationship is further substantiated by the characteristics of field-dependent and field-independent learners. According to Witkin et al. (1977), field-dependent learners are described as socially oriented and with preference for interaction and communication with others in groups. In contrast, field-independent learners are characterized as impersonally oriented. This is also confirmed by a study about the effect of a hypermedia environment, conducted with 177 students (Summerville, 1999). Interviews with the participants showed that field-dependent learners prefer more step-by-step instructions with more human direction. This shows again that social interaction is important for field-dependent learners. Field-dependent and field independent learners are classified in the low working memory capacity and high working memory capacity groups respectively in the above discussion. Therefore, this is another indication for a link between low working memory capacity and an active learning style as well as between high working memory capacity and a reflective learning style.

Another study, which is also in line with the proposed relationship, was conducted by Hadwin, Kirby, and Woodhouse (1999). They have investigated the relationship between note-taking, review, and student ability. The results of this study showed that students with high working memory capacity performed better in class when they primarily listened during lectures and reviewed notes provided by the lecturer. While this result is initially somewhat surprising, it is quite in line with our reasoning. According to Felder and Silverman (1988), reflective learners need time to think and reflect about the learned material and “... do not learn much in situations that provide no opportunity to think about the information being presented (such as most lectures)" (p. 678). Providing notes for learners gives them more time to listen and reflect, which is especially important for reflective learners. Because reflective learners as well as learners with high working memory capacity learn better when they have more time to listen, this study supports the above argued interaction between a reflective learning style and high working memory capacity.

Beacham, Szumko, and Alty's (2003) study was also in agreement with our line of reasoning by showing that $73 \%$ of the dyslexic learners (low working memory capacity) have the active learning style and $27 \%$ have the reflective learning style.

From all evidence above, postulation about the relationships can be made between active learning style and low working memory capacity, and between reflective learning style and high working memory capacity. 


\subsection{Working Memory Capacity and the Verbal-Visual Dimension}

Although several views have suggested that working memory consists of separate components for verbal and nonverbal information (Paivio, 1986; Baddeley, 1986), there are also studies that do not emphasize the structural view of working memory: Salthouse and Babcock (1991) as well as Daneman and Carpenter (1980) viewed working memory as a process; and Atkinson and Shiffrin (1968) defined working memory as the gateway allowing information to be transferred to the long-term memory. In the study from Beacham, Szumko, and Alty (2003) quoted in the discussion below, working memory is viewed as a whole instead of divided components.

Beacham, Szumko, and Alty (2003) found that $97 \%$ of the dyslexic learners are visual learners and the remaining 3\% also sat just in the mild-verbal range. They further stated that "this was to be expected since dyslexic people do tend to be talented in the areas of creativity and visual thinking” (Beacham, Szumko, and Alty 2003, p. 23 quoting West 1997; Mortimore, 2003). Beacham, Szumko, and Alty (2003) further quoted McLoughlin’s (2001) work, which stated “An inefficient working memory will clearly undermine skill acquisition and learning. Describing dyslexia ... [as a working memory deficit] ... can help explain both the persisting writing language difficulties” (p. 16), as a rationale to explain why low working memory would cause problem in reading comprehension. This rationale is in agreement with Simmons and Singleton's (2000) view that the cause of inability to solve inferential problems (and thus dyslexia) is due to insufficient working memory capacity. Comprehension of text would certainly be undermined by insufficient capacity to buffer what was read before. It is fair to argue that learners with severe deficiencies in working memory would have problems in reading, meaning dyslexia, and according to Beacham, Szumko, and Alty (2003) would likely prefer visual learning.

The study by Wey and Waugh (1993) supports this conclusion. Wey and Waugh have investigated the performance of 61 students when working either with text-only based instructions or instructions with text and graphics. In the text-only group field-independent learners performed better than field-dependent learners. No significant differences were found in the group using text and graphics. In other words, fielddependent learners have difficulties in learning text-only material and benefit more from material that contains text as well as graphics. In reference to the discussion above that field-independent learners tend to 
have high working memory capacity and field-dependent learners low working memory capacity, the results of Wey and Waugh's study are in line with the studies about dyslexia. Both argue that learners with low working memory capacity (and a field-dependent cognitive style) benefit from visual material and therefore prefer a more visual learning style.

\subsection{Working Memory Capacity and the Sequential-Global Dimension}

The empirical study by Huai (2000) investigated the relation between working and long-term memory capacities and a serial/holistic learning style. The difference between holistic (described in Huai, 2000) and global learning style (described in Felder and Silverman, 1988) is only nominal. The same applies to serial and sequential learning styles. Results of Huai's study show that learners with an holistic/global learning style have significantly smaller working memory than learners with serial/sequential learning style (those who are highly capable to follow and remember sequentially fixed information).

According to Witkin et al. (1977) and Felder and Silverman (1988), field-independent learners, like sequential learners, can easily learn material that is separated from its context whereas field-dependent learners, like global learners, learn best when given a large context in which to embed new learning. Furthermore, field-independent learners are considered as analytical, equal to serial learners, and fielddependent learners are characterized as more global, like holistic learners. This is also confirmed, for example, by the study by Liu and Reed (1994), investigating the behaviour of 63 students in hypermediaassisted language learning.

The study by Ford and Chen (2000) also investigated the interaction between fielddependence/independence and holistic/serial biases. Also this study drew conclusions about the behaviour of students in a hypermedia learning environment and investigated the interaction between individual differences, learning behaviour, and learning outcome. Individual differences also include cognitive styles like holistic and serial biases according to Pask (1976) and field-dependence and independence according to Witkin et al. (1977). The results showed several patterns, for example, the navigation mode and the interest in specific kinds of learning objects that link holistic (global) and field-dependent styles as well as serial (sequential) and field-independent styles. At this point we also want to mention that some similarities exist 
between serial and field-dependent learners as well as between holistic and field-independent learners. For example, both serial and field-dependent learners tend to preserve the original order or structure of a course during the learning process. However, according to the scores of the personality tests a significant correlation between an holistic and field-dependent cognitive style and a serial and field-independent cognitive style was detected in the study. Similar results are also recorded by several other studies (Ford and Chen, 2000, quoting Ash, 1986; Brumby, 1982; Entwistle, 1981; Jonassen and Grabowski, 1993; Riding and Cheema, 1991).

As a consequence, the findings about field-dependence/independence and holistic/serial biases support our reasoning that learners with high working memory capacity (and therefore a tendency to fieldindependence) are likely to prefer a serial and respectively sequential learning style whereas learners with low working memory capacity (likely to be considered as field-dependent) tend to have an holistic and respectively global learning style.

Beacham, Szumko, and Alty (2003) had also recorded higher preference (14\% higher) of global learning style to sequential learning style among dyslexic learners (low working memory capacity). They quoted another supportive finding from Mortimore (2003) saying that "dyslexic learners are inclined to focus more successfully upon of any topic rather than its details and sequences of information” (Beacham, Szumko, and Alty, 2003, p. 24).

All sources are pointing to the link between high working memory capacity and sequential learners, and low working memory capacity and global learners.

\section{Results and Benefits of the Relationship between Learning Styles and Cognitive Traits}

The results of current investigations show that relationships exist between working memory capacity and the four dimensions of Felder-Silverman learning style model. Table 1 summarises the discussed relationships. It should be pointed out that these relationships show tendencies. For example, current investigation indicates that most of the learners with high working memory capacity tend to have a reflective learning style and viceversa.

Insert Table 1 about here 
There are two benefits of the identified relationship between cognitive traits and learning styles. The first benefit is for adaptive systems that are able to detect either only learning styles or only cognitive traits. For these systems, the relationship yields additional information. For example, a system that is able to detect only learning styles can use the identified relationships to get also some information about the cognitive abilities of each learner. This additional information can be used to provide adaptivity not only for learning styles but also for cognitive traits.

The second benefit of the interaction between learning styles and cognitive traits refers to improving the student model of systems that are able to detect both, learning styles and cognitive traits. In the previous case the student model includes information about either only learning styles or only cognitive traits and is extended by information about the other one. In this case, the student model already includes both, learning styles and cognitive traits, and the identified interaction between learning styles and cognitive traits can be used to build a more reliable student model. Detecting learning styles and cognitive traits is a complex process. As mentioned in the introduction, a meaningful approach for detecting them is to track the behaviour of learners during an online course and infer their learning styles and cognitive traits from this behaviour. This process needs a lot of interaction between the learners and the system and therefore takes time to provide a reliable conclusion about their learning styles and cognitive traits.

The relationship between learning styles and cognitive traits can verify the detection process and hence improve the reliability of the student model. Referring to the CTM, the information about learning styles can be treated similarly to the information about Manifestations of Traits. Accordingly, the information about each learning style dimension can be corresponded to a node in each Individualised Temperament Network and can be used as additional data to calculate cognitive traits. Likewise, the information about cognitive traits can be treated similarly to information about patterns of behaviour relevant for learning styles. Again, the additional information can be included in the calculation process of learning styles. Incorporating more data in the calculation processes leads to a more reliable result and therefore improves student modelling.

\section{Conclusion \& Future Work}


The aim of this paper is to identify interactions between learning styles and cognitive traits. Considering the learning style, we based our investigations on the Felder-Silverman learning style model. As an example for cognitive traits, working memory capacity was applied. As a result, interactions between the dimensions of the learning style model and working memory capacity have been identified. Learners with low working memory capacity tend to prefer an active, sensing, visual, and global learning style. On the other hand, learners with high working memory capacity tend to be reflective, intuitive, and sequential.

The results of the paper show that a relationship exists between learning styles and cognitive traits. This relationship can be used, on the one hand, to get additional information about the learners in systems which are able to detect either only learning styles or only cognitive traits. For systems that already consider both, learning styles and cognitive traits, the relationship can be used to build a more robust student model. Especially, when identifying learning styles and cognitive traits from the behaviour and responses of learners during an online course, sufficient information is required. Including the information about learning styles in the detection process of cognitive traits and vice versa, provides additional information which can be used to improve dynamic student modelling.

Future work will include experimental investigations to verify the identified relationship. Furthermore, future work will deal with the question of how strongly the cognitive traits interact with the learning styles. Analysing the tracked data from a system that incorporates cognitive traits as well as learning styles will deliver a detailed insight into the interrelation of cognitive traits and learning styles. In addition, future work will include further investigations concerning other cognitive traits, such as inductive reasoning skills, associative learning skills, and information processing speed.

\section{Acknowledgement}

This research has been partly funded by the Austrian Federal Ministry for Education, Science, and Culture, and the European Social Fund (ESF) under grant 31.963/46-VII/9/2002 and partly by Online Learning Systems Ltd in conjunction with the New Zealand Foundation for Research, Science \& Technology

\section{References}


Al-Naeme, F.F.A. (1991). The influence of various learning styles on practical problem-solving in chemistry in Scottish secondary schools, Ph.D. thesis, University of Glasgow.

Atkinson, R.C., and Shiffrin, R.M. (1968). Human memory: A proposed system and its control processes. In K.W. Spence and J.T. Spence, The Psychology of Learning and Motivation: Advances in Research and Theory, vol. 2., New York: Academic Press.

Baddeley, A.D. (1986). Working Memory. Oxford: Oxford University Press.

Bahar, M., and Hansell, M.H. (2000). The Relationship Between Some Psychological Factors and their Effect on the Performance of Grid Questions and Word Association Tests. Educational Psychology 20 (3), 349-364. Retrieved 23 July, 2005, from http://taylorandfrancis.metapress.com/media/253X525GYN5YNJKT9T0M/Contributions/ 2/6/J/V/26JVEGAUXF3TTEXR.pdf

Beacham, N., Szumko, J., and Alty, J. (2003). An initial study of computer based media effects on learners who have dyslexia. Final Report. Loughborough University. Retrieved 20 July, 2005, from http://www.techdis.ac.uk/resources/files/MediaEffectsOnDyslexiaBeacham.pdf

Brusilovsky, P. (1994). The Construction and Application of Student Models in Intelligent Tutoring Systems. Journal of computer and systems sciences international 32 (1), 70-89. Retrieved 23 July, 2005, from http://www2.sis.pitt.edu/ peterb/papers/studentmodels.pdf

Calvo, M.G. (2001). Working memory and inferences: Evidence from eye fixations during reading. In. S.E. Gathercole, Short-term and working memory. East Sussex: Psychology Press Ltd. Retrieved 20 July, 2005, from http://taylorandfrancis.metapress.com/media/F2779F55MJ3UQL5GDMWK/Contributions/1/M/2/J/1M2JWRTB0T6 EGP7F.pdf

Carver, C.A., Howard, R.A., and Lane, W.D. (1999). Addressing different learning styles through course hypermedia. IEEE Transactions on Education 42 (1), 33-38.

Daneman, M., and Carpenter, P.A. (1980). Individual differences in working memory and reading. Journal of Verbal Learning and Verbal Behaviour 19, 450-466.

Davis, J.K. (1991). Educational implications of field dependence-independence. In S. Wapner and J. Demick, Field Dependence-Independence: Cognitive style across the life span (149-176). Mahwah: Lawrence Erlbaum Associates.

Deary, I.J., Whiteman, M.C., Starr, J.M., Whalley, L.J., and Fox, H.C. (2004). The Impact of Childhood Intelligence on Later Life: Following Up the Scottish Mental Surveys of 1932 and 1947. Journal of Personality and Social Psychology 86 (1), 130-147, American Psychological Association, Inc. 
El-Banna, H. (1987). The development of a predictive theory of science education based upon information processing theory, Ph.D. thesis, University of Glasgow.

Fabregat, R., Marzo, J.L., and Peña, C.I. (2000). Teaching Support Units. Computers and Education in the 21st Century (pp. 163-174), Kluwer Academic Publishers.

Felder, R.M., and Silverman, L.K. (1988). Learning and Teaching Styles in Engineering Education. Engineering Education 78 (7), 674-681. Preceded by a preface in 2002: http://www.ncsu.edu/felderpublic/Papers/LS-1988.pdf (retrieved 23 July, 2005).

Felder, R.M., and Soloman B.A. (1997). Index of Learning Styles Questionnaire, Online version. Retrieved 6 February, 2006, from http://www.engr.ncsu.edu/learningstyles/ ilsweb.html

Ford, N., and Chen, S.Y. (2000). Individual differences, hypermedia navigation and learning: An empirical study. Journal of Educational Multimedia and Hypermedia 9 (4), 281-312. Retrieved 23 July, 2005, from http://www.brunel.ac.uk/ csstsyc/ JEMH94281.pdf

García, P., Amandi, A., Schiaffino, S., and Campo, M. (2006). Evaluating Bayesian Networks' Precision for Detecting Students' Learning Styles. Computers \& Education, Elsevier. Retrieved 26. February, 2006, from http://authors.elsevier.com/sd/article/S0360131505001788

Graf, S., and Kinshuk (2006). An Approach for Detecting Learning Styles in Learning Management Systems. Proceedings of the International Conference on Advanced Learning Technologies (pp. 161-163), Kerkrade, Netherlands.

Hadwin, A.F., Kirby, J.R., and Woodhouse, R.A. (1999). Individual differences in note-taking, summarization and learning from lectures. Alberta Journal of Educational Research 45 (1), 1-17.

Honey, P., and Mumford, A. (1982). The manual of Learning Styles. Peter Honey Maidenhead

Huai, H. (2000). Cognitive style and memory capacity: effects of concept mapping as a learning method. Ph.D. thesis, Oct 2000, Twente University, The Netherlands.

Hudson, L. (1966). Contrary Imaginations. London: Penguin Books.

Jeffries, S., and Everatt, J. (2004). Working Memory: Its Role in Dyslexia and Other Specific Learning Difficulties. Dyslexia 10 (3), 196-214. Retrieved 20 July, 2005, from http://www3.interscience.wiley.com/cgibin/fulltext/109568421/PDFSTART

Kinshuk, and Lin, T. (2005). Adaptive Approaches in Web Learning Communities - Enhancing the Quality of Technical and Vocational Education. Proceedings of the UNESCO-UNEVOC/JSiSE International Seminar on Human 
Development for Knowledge Based Society (pp. 113-132). Japan. Retrieved 23 July, 2005, from http://infosys.massey.ac.nz/ kinshuk/papers/2005_unesco_japan.pdf

Kolb, D.A. (1984). Experiential Learning: Experience as the Source of Learning and Development. Englewood Cliffs, New Jersey: Prentice-Hall.

Lin T., and Kinshuk (2005). Cognitive profiling in life-long learning. In C. Howard, J.V. Boettcher, L. Justice, K. Schenk, P.L. Rogers, and G.A. Berg, Encyclopedia of International Computer-Based Learning (pp. 245-255). Hershey, PA: Idea Group Inc. Retrieved 23 July, 2005, from http://infosys.massey.ac.nz/ kinshuk/papers/ 2005_encyclopedia_cognitive.pdf

Lin T., Kinshuk, and Patel A. (2003). Cognitive Trait Model - A Supplement to Performance Based Student Models. Proceedings of International Conference on Computers in Education (pp. 629-632). Hong Kong. Retrieved 5 October, 2005, from http://infosys.massey.ac.nz/ kinshuk/papers/icce2003_ctm.pdf

Liu, M., and Reed, M.R. (1994). The relationship between the learning strategies and learning styles in a hypermedia environment. Computers in Human Behavior, 10(4), 419-434.

Miller, G. (1956). The magic number seven, plus or minus two: Some limit of our capacity for processing information. Psychology Review, 63 (2), 81-96.

Paivio, A. (1986). Mental representations. New York: Oxford University Press.

Pascal-Leone, J. (1970). A mathematical model for the transition rule in Piaget’s development stages, Acta Psychologica 32, 301-345.

Pask, B. (1976). Styles and strategies of learning. British Journal of Educational Psychology 46 (2), 128-148.

Peña, C.I., Marzo, J.L., and De la Rosa, J.L. (2002). Intelligent Agents in a Teaching and Learning Environment on the Web. Proceedings of the International Conference on Advanced Learning Technologies. Retrieved 8 March, 2006, from http://eia.udg.es/ clarenes/docs/icalt94.pdf.

Richards-Ward, L.A. (1996). Investigating the relationship between two approaches to verbal information processing in working memory: An examination of the construct of working memory coupled with an investigation of meta-working memory, Massey University, Palmerston North, New Zealand.

Santrock, J.W. (2005). Psychology. Boston: McGraw-Hill, $7^{\text {th }}$ edition.

Salthouse, T.A., and Babcock, R. (1991). Decomposing adult age differences in working memory. Developmental Psychology 27, 763-776. 
Salthouse, T.A., Mitcheel, D.R.D., Skovronek, E., and Babcock, R.L. (1989). Effects of adult age and working memory on reasoning abilities. Journal of Experiemental Psychology: Learning, Memory, and Cognition 15, 507-516.

Scandura, J.M. (1973). Structural Learning I: Theory and Research. London: Gordon \& Breach.

Simmons, F., and Singleton, C. (2000). The Reading Comprehension Abilities of Dyslexic Students in Higher Education. Dyslexia 6 (3), 178-192. Retrieved 20 July, 2005, from http://www3.interscience.wiley.com/cgibin/fulltext/72516239/PDFSTART

Summerville, J. (1999). Role of awareness of cognitive style in hypermedia. International Journal of Educational Technology, July 1999, Vol. 1, No. 1. Electronic version, retrieved 6 March, 2006, from http://www.ao.uiuc.edu/ijet/v1n1/summerville/index.html.

Wey P., and Waugh M.L. (1993). The Effects of Different Interface Presentation Modes and Users' Individual Differences on Users' Hypertext Information Access Performance. Paper presented at the Annual Meeting of the American Educational Research Association, Atlanta, GA.

Witkin, H.A., Moore, C.A., Goodenough, D.R., and Cox, P.W. (1977). Field dependent and field independent cognitive styles and their educational implications. Review of Educational Research. 47 (1), 1-64.

\section{Authors' Vitae}

\section{Sabine Graf}

Sabine Graf is graduate researcher at Women's Postgraduate College for Internet Technologies at Vienna University of Technology, Austria. She is also researcher at Advanced Learning Technology Research Centre of Massey University, New Zealand. Her research interests include adaptivity in web-based educational systems, student modelling, and artificial intelligence.

\section{Taiyu Lin}

Taiyu Lin is Graduate Researcher at the Advanced Learning Technology Research Centre of Massey University, New Zealand. He is also Assistant Editor of the Journal of Educational Technology \& Society (ISSN 1436-4522). He is also Secretary of New Zealand Chapter of ACM. His research interests include exploratory learning, human cognition, and learner profiling. 


\section{Kinshuk}

Kinshuk joined Athabasca University in August 2006 as the Professor and Director of School of Computing and Information Systems. Before moving to Canada, Kinshuk worked at German National Research Centre for Information Technology as Postgraduate Fellow, and at Massey University, New Zealand as Associate Professor of Information Systems and Director of Advanced Learning Technology Research Centre. He also holds Honorary Senior E-Learning Consultant position with Online Learning Systems Ltd., New Zealand, and Docent position with University of Joensuu, Finland. He has been involved in large-scale research projects for exploration based adaptive educational environments and has published extensively in international refereed journals, conferences and book chapters. He is Chair of IEEE Technical Committee on Learning Technology and International Forum of Educational Technology \& Society. He is also editor of the SSCI indexed Journal of Educational Technology \& Society (ISSN 1436-4522).

\section{Figures}

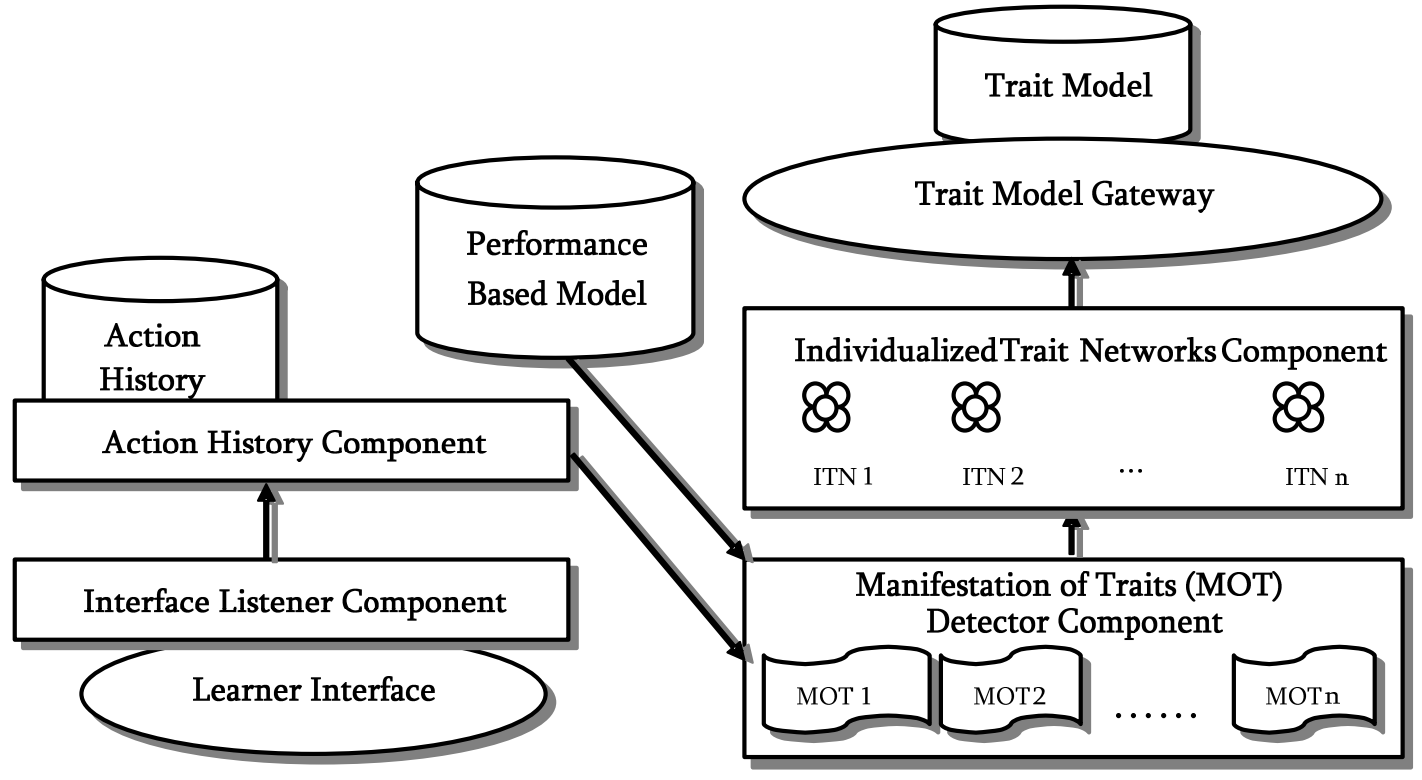

Figure 1. Structural View of Cognitive Trait Model 


\section{Tables}

Table 1. Mapping of Felder-Silverman learning style dimensions and working memory capacity

\begin{tabular}{|c|c|}
\hline & High Working Memory Capacity Low Working Memory Capacity \\
\hline \multirow{8}{*}{ 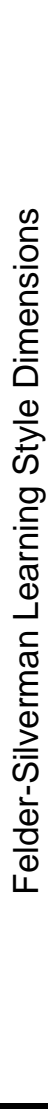 } & $\begin{array}{ll}\text { Reflective } & \text { Active } \\
\end{array}$ \\
\hline & $\begin{array}{c}\text { Beacham, Szumko, and Alty (2003) } \\
\text { Hadwin, Kirby, and Woodhouse (1999) } \\
\text { Kolb (1984) } \\
\text { Summervill (1999) } \\
\text { Witkin et al. (1977) }\end{array}$ \\
\hline & Intuitive Sensing \\
\hline & $\begin{array}{c}\text { Bahar and Hansell (2000) } \\
\text { Davis (1991) } \\
\text { Ford and Chen (2000) } \\
\text { Hudson (1966) } \\
\text { Kinshuk and Lin (2005) } \\
\text { Scandura (1973) } \\
\text { Witkin et al. (1977) }\end{array}$ \\
\hline & Verbal or Visual Visual \\
\hline & $\begin{array}{c}\text { Beacham, Szumko, and Alty (2003) } \\
\text { Simmons and Singleton (2000) } \\
\text { Wey and Waugh (1993) }\end{array}$ \\
\hline & Sequential \\
\hline & $\begin{array}{c}\text { Beacham, Szumko, and Alty (2003) } \\
\text { Ford and Chen (2000) } \\
\text { Huai (2000) } \\
\text { Liu and Reed (1994) } \\
\text { Mortimore (2003) } \\
\text { Witkin et al. (1977) }\end{array}$ \\
\hline \multirow{6}{*}{ 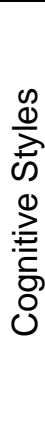 } & Field-independent $\quad$ Field-dependent \\
\hline & $\begin{array}{c}\text { Al-Naeme (1991) } \\
\text { Bahar and Hansell (2000) } \\
\text { El-Banna (1987) } \\
\text { Pascual-Leone (1970) }\end{array}$ \\
\hline & Divergent Convergent \\
\hline & Bahar and Hansell (2000) \\
\hline & Holistic \\
\hline & Huai (2000) \\
\hline
\end{tabular}

